ISSN 1420-3049

www.mdpi.org/molecules

Article

\title{
Design, Synthesis, and Antitumor Activities of Some Novel Substituted 1,2,3-Benzotriazines
}

\author{
Jin-Ling Lv ${ }^{1}$, Rui Wang ${ }^{1}$, Dan Liu ${ }^{1}$, Gang Guo ${ }^{1}$, Yong-Kui Jing ${ }^{2}$ and Lin-Xiang Zhao ${ }^{1{ }^{\prime} *}$ \\ ${ }^{1}$ Shenyang Pharmaceutical University, Shenyang, 110016, P.R. China; E-mails: \\ jinlinglv12@yahoo.com.cn (Lv); ruiwang36@yahoo.com.cn (Wang); sammyld@163.com(Liu); \\ guogang19761126@sina.com (Guo) \\ 2 Mount Sinai School of Medicine, One Gustave L. Levy Place, New York, NY 10029, USA; \\ E-mail: yongkui.jing@mssm.edu
}

* Author to whom correspondence should be addressed. E-mail: zhaolinxiang@syphu.edu.cn; Tel.: (+86)24-23986420; Fax: (+86)24-23986420.

Received: 5 June 2008; in revised form: 22 June 2008 / Accepted: 23 June 2008 / Published: 24 June 2008

\begin{abstract}
A series of novel substituted 1,2,3-benzotriazines based on the structures of vatalanib succinate (PTK787) and vandetanib (ZD6474) were designed and synthesized. The antiproliferative effects of these compounds were tested on microvascular endothelial cells (MVECs) using the MTT assay. Introduction of a methoxy and a 3-chloropropoxy group into the 1,2,3-benzotriazines increased the antiproliferative effects. 4-(3-Chloro-4fluoroanilino)-7-(3-chloropropoxy)-6-methoxy-1,2,3-benzotriazine $(\mathbf{8 m})$ was the most effective compound. It was 4-10 fold more potent than PTK787 in inhibiting the growth of T47D breast cancer cells, DU145 and PC-3 prostate cancer cells, LL/2 murine Lewis lung cancer cells and B16F0 melanoma cells.
\end{abstract}

Keywords: 1,2,3-Benzotriazine, synthesis, antiproliferative activity, vatalanib succinate. 


\section{Introduction}

Vascular endothelial growth factor (VEGF) plays an important role in both physiological and pathological angiogenesis by binding to its receptor, VEGFR [1]. The expression of VEGFR is increased in the majority of cancers and is associated with survival, migration and invasion of solid tumor cells [1]. Elevated VEGF levels have been found to increase resistance to chemotherapy [2, 3] and VEGF signaling has been used as a therapeutic target for the treatment of cancer. VEGFR inhibitors such as vatalanib succinate (PTK787/ZK222584) and vandetanib (ZD6474) have been used in clinical trials in several types of cancer [4-7]. Although both agents showed antitumor activities alone, combinations with chemotherapeutic agents seem to be required for reaching therapeutic effects [8-12]. To improve the antiproliferative abilities of PTK787 and ZD6474 (Figure 1), we have analyzed the structures of PTK787 and ZD6474. PTK787 contains 2,3-benzodizine and ZD6474 contains 1,3benzodizine. We thought that the replacement of the benzodizine with 1,2,3-benzotriazine might have increased activities compared to PTK787. Thus, we designed and synthesized eighteen novel compounds (8a-m) with a basic 1,2,3-benzotriazine scaffold and the introduction of a methoxy group or a short alkoxy group. The antiproliferative effects of these compounds were determined in microvascular endothelial cells (MVECs) using MTT assay and the antiproliferative effects of compound $\mathbf{8 m}$ were found to be the most profound in inhibiting growth of MVECs. Therefore, it was further investigated in T47D breast cancer cells, DU145 and PC-3 prostate cancer cells, LL/2 murine Lewis lung cancer cells and B16F0 melanoma cells.

Figure 1. Structures of vatalanib succinate (PTK787) and vandetanib (ZD6474).<smiles>O=C(O)CCC(=O)O</smiles>

PTK787<smiles>COc1cc2c(Nc3ccc(Br)cc3F)ncnc2cc1OCC1CCN(C)CC1</smiles>

ZD6474

\section{Results and Discussion}

Design and synthesis of novel 1,2,3-benzotriazines

Recently, it was reported that 1,2,4-benzotriazines were inhibitors of Src and the binding model of 1,2,4-benzotriazines with Src showed the importance of the N1 and N2 atoms [13, 14]. We considered that VEGFR and Src might react with substrates in a similar fashion as both of them are tyrosine kinases. Both PTK787 and ZD6474 contain a substituted anilino group. ZD6474 contains a methoxy group at the $\mathrm{C} 6$ position and a short side chain at the $\mathrm{C} 7$ position. We thought that these substituents 
are required for the antitumor activity. Thus, we decided using 1,2,3-benzotriazine to replace the phthalazine in PTK787 or the quinazoline in ZD6474 and to add a methoxy group at the C6 position and a short alkoxy group at the $\mathrm{C} 7$ position of 1,2,3-benzotriazine. A series of target compounds, 8a-r, were obtained and their structures are listed in Table 1.

Compounds 8a-r were prepared according to the synthetic route outlined in Scheme 1. 4-Cyano-2methoxyphenol (1) reacted with various alkyl halides to afford intermediates 2a-c in satisfactory yields. Compounds 2a-c were selectively nitrated at $30{ }^{\circ} \mathrm{C}$ to give nitro compounds 3a-c in $87-95 \%$ yields. The reduction of the nitro compounds 3a-c to the corresponding amines $4 \mathbf{a}-\mathbf{c}$ was catalyzed by $\mathrm{Pd} / \mathrm{C}$ [15]. Compounds 4a-c were diazotized and then coupled with substituted anilines at $0{ }^{\circ} \mathrm{C}$, followed by chromatographic purification to afford triazenes $\mathbf{6 b}-\mathbf{r}$. Compound $\mathbf{6 a}$ was prepared by the coupling of diazotized 2-aminobenzonitrile (5) and 4-chloroaniline. The cyclization of compounds 6a$\mathbf{r}$ in $70 \%$ ethanol formed intermediates 7a-r, which then rearranged to compounds 8a-r after refluxing in acetic acid [16]. As intermediates 7a-r were unstable, they were used directly in the next step without further purification.

Scheme 1. Synthetic route to the target compounds.
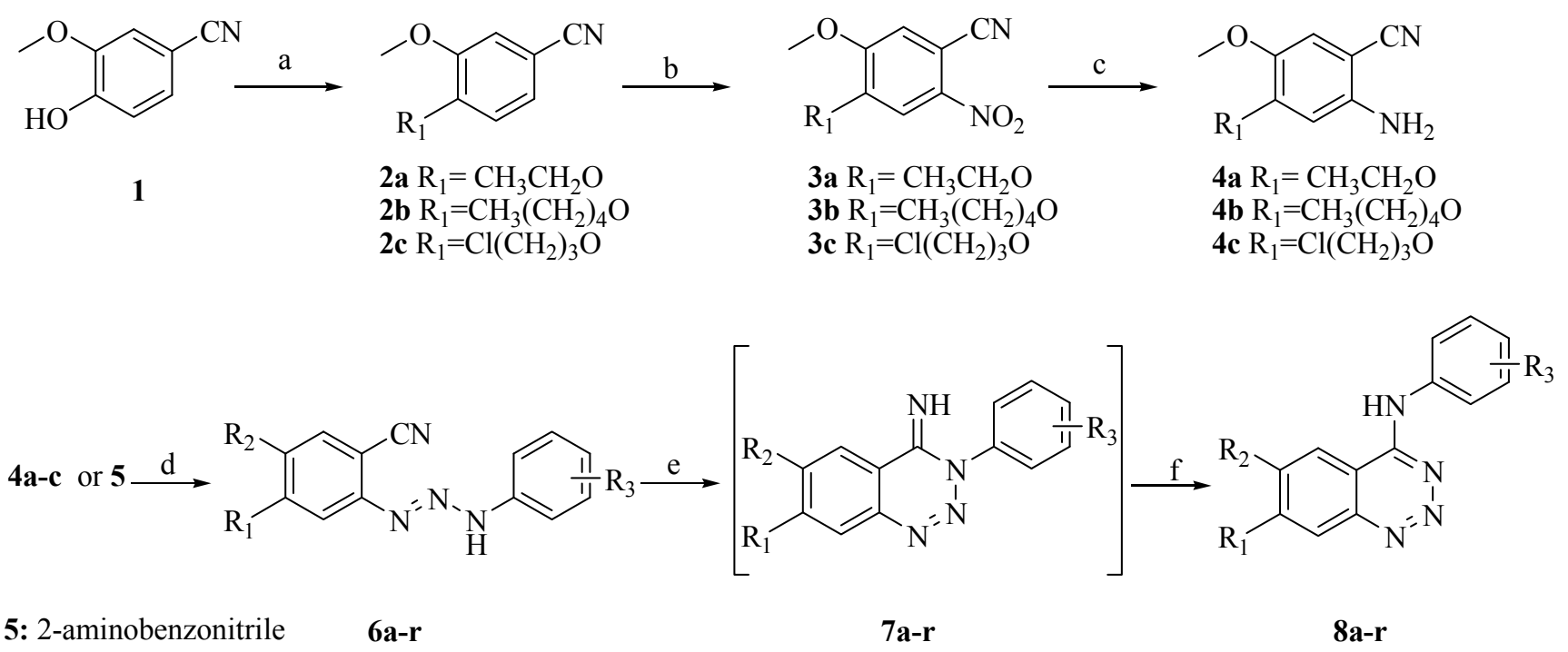

Reagents and conditions: (a) alkyl halides, DMF, $\mathrm{K}_{2} \mathrm{CO}_{3}, 37{ }^{\circ} \mathrm{C}$; (b) $\mathrm{HNO}_{3}, 30{ }^{\circ} \mathrm{C}$; (c) $\mathrm{Pd} / \mathrm{C}$, cyclohexene, ethanol, reflux; (d) $\mathrm{NaNO}_{2} / \mathrm{HCl}, 0{ }^{\circ} \mathrm{C}$; substituted aniline, $0{ }^{\circ} \mathrm{C}$; (e) $70 \%$ ethanol, reflux; (f) $\mathrm{AcOH}$, reflux.

\section{Antiproliferative activities in MVECs}

The antiproliferative effects of compounds 8a-r in MVECs were determined (Table 1) and the structure-activity relationships were analyzed. The results revealed that compounds with a methoxy group $\left(\mathrm{R}_{2}\right)$ at the $\mathrm{C} 6$ position and an alkoxy group $\left(\mathrm{R}_{1}\right)$ at the $\mathrm{C} 7$ position $(\mathbf{8 b}-\mathbf{r})$ had an increased activity compared to that of compound 8a which did not have substitutions at the $\mathrm{C} 6$ and $\mathrm{C} 7$ positions. The compounds with a 3-chloropropoxy group $\left(\mathrm{R}_{1}\right)$ at the $\mathrm{C} 7$ position $(\mathbf{8 h}-\mathbf{r})$ were more active than compounds with an ethoxy group $(\mathbf{8 b}-\mathbf{d})$ or a pentyloxy group $(\mathbf{8 e -} \mathbf{- g})$. 
By comparing the activities of compounds with a methoxy group at the C6 position and a 3chloropropoxy group at the $\mathrm{C} 7$ position, but with a different substituted group $\left(\mathrm{R}_{3}\right)$ at the $\mathrm{C} 4$ anilino group (8h-r), it revealed that a substitution at the $\mathrm{C} 4$ anilino increased the antiproliferative activity in MVECs compared to compound 8r, which did not have a substitution at the C4 anilino group. The electronic effect of a substituent on the anilino group did not influence the antiproliferative activities (comparing compounds 8k-o). Compounds with two substituents at the C3' and C4' positions of the C4 anilino group (8i, $\mathbf{8 m}$, and $\mathbf{8 p}$ ) were more active than compounds with two substituents at the C3' and $\mathrm{C}^{\prime}$ ' positions $(\mathbf{8 h})$ or compounds with one substituent $(\mathbf{8 j}, \mathbf{8 k}, \mathbf{8 1}, \mathbf{8 n}, \mathbf{8 0}, \mathbf{8 q})$. Compound $\mathbf{8 m}$ was the most potent one in inhibiting proliferation of MVECs with a $\mathrm{GI}_{50}$ value of $7.98 \mu \mathrm{M}$. The compounds with substituents at the anilino group (compounds 8h-q) were more effective than PTK787 in inhibiting growth of MVECs after the introduction of a methoxy group at the C6 position and a 3chloropropoxy group at the $\mathrm{C} 7$ position.

Table 1. The structures of target compounds and their antiproliferative effects in MVECs.

\begin{tabular}{ccccc}
\hline Compounds & $\mathbf{R}_{\mathbf{1}}$ & $\mathbf{R}_{\mathbf{2}}$ & $\mathbf{R}_{\mathbf{3}}$ & $\mathbf{G I}_{\mathbf{5 0}}(\boldsymbol{\mu} \mathbf{M})^{\mathbf{a}}$ \\
\hline $\mathbf{8 a}$ & $\mathrm{H}$ & $\mathrm{H}$ & $4-\mathrm{Cl}$ & $>80$ \\
$\mathbf{8 b}$ & $\mathrm{CH} \mathrm{CH}_{2} \mathrm{O}$ & $\mathrm{CH}_{3} \mathrm{O}$ & $4-\mathrm{Cl}$ & $26.54 \pm 1.43$ \\
$\mathbf{8 c}$ & $\mathrm{CH}_{3} \mathrm{CH}_{2} \mathrm{O}$ & $\mathrm{CH}_{3} \mathrm{O}$ & $4-\mathrm{CH}_{3}$ & $42.56 \pm 2.79$ \\
$\mathbf{8 d}$ & $\mathrm{CH}_{3} \mathrm{CH}_{2} \mathrm{O}$ & $\mathrm{CH}_{3} \mathrm{O}$ & $3-\mathrm{Cl}, 4-\mathrm{F}$ & $38.81 \pm 1.86$ \\
$\mathbf{8 e}$ & $\mathrm{CH}_{3}\left(\mathrm{CH}_{2}\right)_{4} \mathrm{O}$ & $\mathrm{CH}_{3} \mathrm{O}$ & $4-\mathrm{Cl}$ & $25.35 \pm 1.02$ \\
$\mathbf{8 f}$ & $\mathrm{CH}_{3}\left(\mathrm{CH}_{2}\right)_{4} \mathrm{O}$ & $\mathrm{CH}_{3} \mathrm{O}$ & $3-\mathrm{OCF}_{3}$ & $42.64 \pm 2.27$ \\
$\mathbf{8 g}$ & $\mathrm{CH}_{3}\left(\mathrm{CH}_{2}\right)_{4} \mathrm{O}$ & $\mathrm{CH}_{3} \mathrm{O}$ & $4-\mathrm{OCF}$ & $37.98 \pm 1.98$ \\
$\mathbf{8 h}$ & $\mathrm{Cl}_{3}\left(\mathrm{CH}_{2}\right)_{3} \mathrm{O}$ & $\mathrm{CH}_{3} \mathrm{O}$ & $3,5-\mathrm{di}-\mathrm{Cl}$ & $28.84 \pm 1.40$ \\
$\mathbf{8 i}$ & $\mathrm{Cl}\left(\mathrm{CH}_{2}\right)_{3} \mathrm{O}$ & $\mathrm{CH}_{3} \mathrm{O}$ & $3,4-\mathrm{di}-\mathrm{Cl}$ & $11.02 \pm 0.49$ \\
$\mathbf{8 j}$ & $\mathrm{Cl}\left(\mathrm{CH}_{2}\right)_{3} \mathrm{O}$ & $\mathrm{CH}_{3} \mathrm{O}$ & $4-\mathrm{Cl}$ & $18.59 \pm 1.31$ \\
$\mathbf{8 k}$ & $\mathrm{Cl}\left(\mathrm{CH}_{2}\right)_{3} \mathrm{O}$ & $\mathrm{CH}_{3} \mathrm{O}$ & $4-\mathrm{CH}_{3}$ & $17.08 \pm 0.65$ \\
$\mathbf{8 1}$ & $\mathrm{Cl}\left(\mathrm{CH}_{2}\right)_{3} \mathrm{O}$ & $\mathrm{CH}_{3} \mathrm{O}$ & $4-\mathrm{F}$ & $23.05 \pm 0.92$ \\
$\mathbf{8 m}$ & $\mathrm{Cl}\left(\mathrm{CH}_{2}\right)_{3} \mathrm{O}$ & $\mathrm{CH}_{3} \mathrm{O}$ & $3-\mathrm{Cl}_{2}, 4-\mathrm{F}$ & $7.98 \pm 0.35$ \\
$\mathbf{8 n}$ & $\mathrm{Cl}\left(\mathrm{CH}_{2}\right)_{3} \mathrm{O}$ & $\mathrm{CH}_{3} \mathrm{O}$ & $3-\mathrm{OCF}$ & $24.86 \pm 0.86$ \\
$\mathbf{8 0}$ & $\mathrm{Cl}\left(\mathrm{CH}_{2}\right)_{3} \mathrm{O}$ & $\mathrm{CH}_{3} \mathrm{O}$ & $4-\mathrm{OCF}$ & $23.19 \pm 1.12$ \\
$\mathbf{8 p}$ & $\mathrm{Cl}\left(\mathrm{CH}_{2}\right)_{3} \mathrm{O}$ & $\mathrm{CH}_{3} \mathrm{O}$ & $3-\mathrm{CF}_{3}, 4-\mathrm{F}$ & $15.22 \pm 0.51$ \\
$\mathbf{8 q}$ & $\mathrm{Cl}\left(\mathrm{CH}_{2}\right)_{3} \mathrm{O}$ & $\mathrm{CH}_{3} \mathrm{O}$ & $3-\mathrm{CF}$ & $21.38 \pm 1.54$ \\
$\mathbf{8 r}$ & $\mathrm{Cl}\left(\mathrm{CH}_{2}\right)_{3} \mathrm{O}$ & $\mathrm{CH}_{3} \mathrm{O}$ & & $>80$ \\
$(\mathbf{P T K}$ & & & & $38.15 \pm 2.07$ \\
\hline
\end{tabular}

a. $\mathrm{GI}_{50}$ is the concentration that inhibits $50 \%$ of cell growth. The cells were treated with various concentrations of the tested compounds for 4 days and cell growth inhibition was determined using the 3-(4,5-dimethylthiazol-2-yl)-2,5-diphenyltetrazolium bromide (MTT) assay. Data shown are means \pm SD of three independent experiments. 
The antiproliferative effects of compound $\mathbf{8 m}$ were then tested in tumor cell lines. The antiproliferative effects of compound $\mathbf{8 m}$ were determined in human T47 breast cancer cells, DU-145 and PC-3 prostate cancer cells, murine LL/2 Lewis lung cancer cells and B16F0 melanoma cells using MTT assay (Table 2). Compound $\mathbf{8 m}$ was more effective than PTK787 to inhibit cell growth in all the tested cell lines.

Table 2. Antiproliferative effects of compound $\mathbf{8 m}$ and PTK787 in several tumor cell lines.

\begin{tabular}{cccccc}
\hline \multirow{2}{*}{ Compounds } & \multicolumn{5}{c}{ GI $_{\mathbf{5 0}}(\boldsymbol{\mu M})^{\mathbf{a}}$} \\
\cline { 2 - 6 } & T47D & DU-145 & PC-3 & LL/2 & B16F0 \\
\hline $\mathbf{8 m}$ & $5.04 \pm 0.32$ & $4.96 \pm 0.43$ & $6.91 \pm 0.30$ & $3.79 \pm 0.19$ & $5.19 \pm 0.22$ \\
PTK787 & $36.32 \pm 1.88$ & $41.28 \pm 2.47$ & $63.68 \pm 3.55$ & $31.15 \pm 2.01$ & $18.71 \pm 1.67$ \\
\hline
\end{tabular}

a. Cells were treated with various concentrations of the tested compounds for 4 days and the cell growth inhibition was determined using the MTT assay. Data shown are means \pm SD of three independent experiments.

\section{Conclusions}

In summary, our data indicate that 1,2,3-benzotriazines substituted with a methoxy group at the C6 position and a 3-chloropropoxy group at the $\mathrm{C} 7$ position exhibit antiproliferative activities. Most of these compounds are more effective than PTK787 in inhibiting proliferation of MVECs. Compound $\mathbf{8 m}$ is the most potent and exhibits greater anti-tumor cell growth activity activities than PTK787. Since we did not stimulate the cell growth of MVECs and tumor cells with VEGF, the observed antiproliferative effects of these compounds, including PTK787, may be through a pathway independent of VEGFR inhibition. Because of the high similarity of 1,2,3-benzotriazine and 1,2,4benzotriazine, the increased antiproliferative effects of the designed compounds in tumor cells may be due to the inhibition of Src, or other tyrosine kinases which is not inhibited by PTK787 [17]. The effects of our novel 1,2,3-benzotriazines on the activities of VEGFRs, Src and other kinases are under investigation.

\section{Experimental}

\section{General}

Reagents (analytical grade) were obtained from commercial suppliers and used without further purification unless otherwise noted. ${ }^{1} \mathrm{H}$ - and ${ }^{13} \mathrm{C}$-NMR spectra were recorded on a Bruker ARX-300 instrument with tetramethylsilane as the internal standard. IR spectra were recorded on a Bruker IR$27 \mathrm{G}$ spectrometer. MS were determined on either Finnigan MAT/USA spectrometer (LC-MS). Elemental analysis was determined on a Carlo-Erba 1106 Elemental analysis instrument (Carlo Erba, Milan, Italy). The melting points were determined on an electrically heated X4 digital visual melting point apparatus and were uncorrected. The structures of the synthesized compounds were characterized 
by melting point (mp), infrared (IR) spectra, nuclear magnetic resonance (NMR) spectra and mass spectral (MS) data.

General procedure for the synthesis of 4-substituted-3-methoxybenzonitriles 2a-c

A solution of 4-cyano-2-methoxyphenol $(1,1.00 \mathrm{~g}, 6.70 \mathrm{mmol})$ in anhydrous DMF $(4.00 \mathrm{~mL})$ was stirred and cooled with a water bath. $\mathrm{K}_{2} \mathrm{CO}_{3}(1.39 \mathrm{~g}, 10.1 \mathrm{mmol})$ was added and the mixture was stirred at $20{ }^{\circ} \mathrm{C}$ for $1 \mathrm{~h}$. The corresponding alkyl halide $(8.13 \mathrm{mmol})$ was added dropwise, the mixture was stirred at room temperature overnight, then heated at $37{ }^{\circ} \mathrm{C}$ for $6 \mathrm{~h}$ and finally poured into a mixture of ice $/ \mathrm{H}_{2} \mathrm{O}(100 \mathrm{~mL})$. After stirring for $10 \mathrm{~min}$, a precipitate was formed. It was filtered off, washed with $\mathrm{H}_{2} \mathrm{O}$, and air-dried to yield the 4-substituted-3-methoxybenzonitriles 2a-c as white solids.

4-Ethoxy-3-methoxybenzonitrile (2a): Yield: 91.8\%; mp: 102-103 ${ }^{\circ} \mathrm{C} .{ }^{1} \mathrm{H}-\mathrm{NMR}\left(\mathrm{DMSO}-\mathrm{d}_{6}\right) \delta$ : 7.36 $(2 \mathrm{H}, \mathrm{m}, \mathrm{H}-2, \mathrm{H}-6), 7.04$ (1H, s, H-5), $4.11\left(2 \mathrm{H}, \mathrm{q}, J=6.9 \mathrm{~Hz}, \mathrm{CH}_{3} \underline{\mathrm{H}}_{2} \mathrm{O}-\right), 3.81$ (3H, s, - $\left.\mathrm{OCH}_{3}\right), 1.35$ $\left(3 \mathrm{H}, \mathrm{t}, J=6.9 \mathrm{~Hz}, \mathrm{CH}_{3} \mathrm{CH}_{2} \mathrm{O}-\right)$; LC-MS: $178.1(\mathrm{M}+\mathrm{H})^{+}$; Anal. Calcd. for $\mathrm{C}_{10} \mathrm{H}_{11} \mathrm{NO}_{2}$ : C 67.78, H 6.26, N 7.90; Found: C 67.79, H 6.24, N 7.91.

3-Methoxy-4-pentyloxybenzonitrile (2b): Yield: 89.0\%; mp: 55-56 ${ }^{\circ} \mathrm{C} .{ }^{1} \mathrm{H}-\mathrm{NMR}$ (DMSO- $\mathrm{d}_{6}$ ) $\delta: 7.37$ (2H, m, H-2, H-6), 7.09 (1H, d, J = 8.1 Hz, H-5), $4.02\left(2 \mathrm{H}, \mathrm{t}, \mathrm{CH}_{3}\left(\mathrm{CH}_{2}\right)_{3} \mathrm{C}_{2} \mathrm{O}-\right), 3.79$ (3H, s, $\left.-\mathrm{OCH}_{3}\right)$, $1.71\left(2 \mathrm{H}, \mathrm{m}, \mathrm{CH}_{3} \mathrm{CH}_{2} \mathrm{CH}_{2} \underline{\mathrm{C}}_{2} \mathrm{CH}_{2} \mathrm{O}-\right), 1.34\left(4 \mathrm{H}, \mathrm{m}, \mathrm{CH}_{3} \underline{\mathrm{C}}_{2} \mathrm{C}_{2}{ }_{2} \mathrm{CH}_{2} \mathrm{CH}_{2} \mathrm{O}-\right), 0.88$ (3H, t, J = 6.9 Hz, $\left.\mathrm{C}_{3} \mathrm{CH}_{2} \mathrm{CH}_{2} \mathrm{CH}_{2} \mathrm{CH}_{2} \mathrm{O}-\right)$; LC-MS: $220.1(\mathrm{M}+\mathrm{H})^{+}$; Anal. Calcd. for $\mathrm{C}_{13} \mathrm{H}_{17} \mathrm{NO}_{2}$ : C 71.21, H 7.81, N 6.39; Found: C 71.20, H 7.80, N 6.39.

4-(3-Chloropropoxy)-3-methoxybenzonitrile (2c): Yield: 87.2\%. ${ }^{1} \mathrm{H}-\mathrm{NMR}$ (DMSO-d 6 ) $\delta$ : 7.41 (2H, m, $\mathrm{H}-2, \mathrm{H}-6), 7.15(1 \mathrm{H}, \mathrm{d}, J=8.8 \mathrm{~Hz}, \mathrm{H}-5), 4.16\left(2 \mathrm{H}, \mathrm{t}, J=6.0 \mathrm{~Hz}, \mathrm{ClCH}_{2} \mathrm{CH}_{2} \mathrm{CH}_{2} \mathrm{O}-\right), 3.79$ (5H, m, $\left.\mathrm{OCH}_{3}, \mathrm{ClCl}_{2} \mathrm{CH}_{2} \mathrm{CH}_{2} \mathrm{O}-\right), 2.20\left(2 \mathrm{H}, \mathrm{m}, \mathrm{ClCH}_{2} \underline{\mathrm{C}}_{2} \mathrm{CH}_{2} \mathrm{O}-\right)$; LC-MS: $226.1(\mathrm{M}+\mathrm{H})^{+}$; Anal. Calcd. for $\mathrm{C}_{11} \mathrm{H}_{12} \mathrm{ClNO}_{2}$ : C 58.54, H 5.36, N 6.21; Found: C 58.52, H 5.37, N 6.20.

General procedure for the synthesis of 4-substituted-5-methoxy-2-nitrobenzonitriles, 3a-c

A solution of 4-substituted-3-methoxybenzonitriles $2(9.10 \mathrm{mmol})$ in nitric acid $(10 \mathrm{~mL})$ was heated to $30{ }^{\circ} \mathrm{C}$ for $2 \mathrm{~h}$, poured into ice-water $(100 \mathrm{~mL})$, filtered, and washed with water to afford compounds 3 as light yellow solids.

4-Ethoxy-5-methoxy-2-nitrobenzonitrile (3a): Yield: 88.1\%; mp: 198-199 ${ }^{\circ} \mathrm{C} .{ }^{1} \mathrm{H}-\mathrm{NMR}$ (DMSO-d 6 ) $\delta$ : $7.85(1 \mathrm{H}, \mathrm{s}, \mathrm{H}-3), 7.70(1 \mathrm{H}, \mathrm{s}, \mathrm{H}-6), 4.25\left(2 \mathrm{H}, \mathrm{q}, J=6.9 \mathrm{~Hz}, \mathrm{CH}_{3} \mathrm{C}_{2} \mathrm{O}-\right), 3.97\left(3 \mathrm{H}, \mathrm{s},-\mathrm{OCH}_{3}\right), 1.37$ $\left(3 \mathrm{H}, \mathrm{t}, J=6.9 \mathrm{~Hz}, \mathrm{C}_{3} \mathrm{CH}_{2} \mathrm{O}-\right)$; LC-MS: $223.1(\mathrm{M}+\mathrm{H})^{+}$; Anal. Calcd. for $\mathrm{C}_{10} \mathrm{H}_{10} \mathrm{~N}_{2} \mathrm{O}_{4}: \mathrm{C} 54.05, \mathrm{H}$ 4.54, N 12.61; Found: C 54.03, H 4.55, N 12.60.

5-Methoxy-2-nitro-4-pentyloxybenzonitrile (3b): Yield: 92.9\%; mp: 136-137 ${ }^{\circ} \mathrm{C} .{ }^{1} \mathrm{H}-\mathrm{NMR}$ (DMSO-d $\mathrm{d}_{6}$ ) $\delta: 7.89$ (1H, s, H-3), 7.80 (1H, s, H-6), $4.16\left(2 \mathrm{H}, \mathrm{t}, J=6.3 \mathrm{~Hz}, \mathrm{CH}_{3} \mathrm{CH}_{2} \mathrm{CH}_{2} \mathrm{CH}_{2} \mathrm{CH}_{2} \mathrm{O}-\right), 3.95$ (3H, s, $\left.\mathrm{OCH}_{3}\right), 1.72\left(2 \mathrm{H}, \mathrm{m}, \mathrm{CH}_{3} \mathrm{CH}_{2} \mathrm{CH}_{2} \mathrm{C}_{2} \mathrm{CH}_{2} \mathrm{O}-\right), 1.35$ (4H, m, $\left.\mathrm{CH}_{3} \underline{\mathrm{C}}_{2} \mathrm{C}_{2} \mathrm{CH}_{2} \mathrm{CH}_{2} \mathrm{O}-\right), 0.89$ (3H, t, $J=$ 
$\left.6.9 \mathrm{~Hz}, \mathrm{CH}_{3} \mathrm{CH}_{2} \mathrm{CH}_{2} \mathrm{CH}_{2} \mathrm{CH}_{2} \mathrm{O}-\right)$; LC-MS: $265.1(\mathrm{M}+\mathrm{H})^{+}$; Anal. Calcd. for $\mathrm{C}_{13} \mathrm{H}_{16} \mathrm{~N}_{2} \mathrm{O}_{4}$ : C 59.08, $\mathrm{H}$ 6.10, N 10.60; Found: C 59.10, H 6.11, N 10.59.

4-(3-Chloropropoxy)-5-methoxy-2-nitrobenzonitrile (3c): Yield: 95.3\%; mp: 133-134 ${ }^{\circ} \mathrm{C} .{ }^{1} \mathrm{H}-\mathrm{NMR}$ $\left(\mathrm{DMSO}_{6}\right) \delta: 7.91(1 \mathrm{H}, \mathrm{s}, \mathrm{H}-3), 7.71(1 \mathrm{H}, \mathrm{s}, \mathrm{H}-6), 4.32\left(2 \mathrm{H}, \mathrm{t}, J=6.0 \mathrm{~Hz}, \mathrm{ClCH}_{2} \mathrm{CH}_{2} \mathrm{C}_{2} \mathrm{O}-\right), 4.00$ $\left(3 \mathrm{H}, \mathrm{s},-\mathrm{OCH}_{3}\right), 3.78\left(2 \mathrm{H}, \mathrm{t}, J=6.3 \mathrm{~Hz}, \mathrm{ClC}_{2} \mathrm{CH}_{2} \mathrm{CH}_{2} \mathrm{O}-\right), 2.23\left(2 \mathrm{H}, \mathrm{m}, \mathrm{ClCH}_{2} \mathrm{CH}_{2} \mathrm{CH}_{2} \mathrm{O}-\right)$; LC-MS: $271.0(\mathrm{M}+\mathrm{H})^{+}$; Anal. Calcd. for $\mathrm{C}_{11} \mathrm{H}_{11} \mathrm{ClN}_{2} \mathrm{O}_{4}$ : C 48.81, H 4.10, N 10.35; Found: $\mathrm{C} 48.82, \mathrm{H} 4.11, \mathrm{~N}$ 10.34 .

General procedure for the synthesis of 4-substituted-2-amino-5-methoxybenzonitriles, 4a-c

A mixture of compound $3(3.69 \mathrm{mmol})$ and $\mathrm{Pd} / \mathrm{C}(10 \%, 7.00 \mathrm{~g})$ in anhydrous ethanol $(10.0 \mathrm{~mL})$ was stirred and heated under reflux. Cyclohexene $(2.30 \mathrm{~mL}, 22.6 \mathrm{mmol})$ was added dropwise. The mixture was refluxed overnight, then cooled to $40{ }^{\circ} \mathrm{C}$, filtered, and washed with ethanol. The filtrate was concentrated to yield a solid. The crude product was suspended in ethanol, stirred at $40{ }^{\circ} \mathrm{C}$ for $30 \mathrm{~min}$, cooled to room temperature, filtered to produce pure compound $\mathbf{4}$ as a yellow solid.

2-Amino-4-ethoxy-5-methoxybenzonitrile (4a): Yield: 49.1\%; mp: 135-136 ${ }^{\circ} \mathrm{C} .{ }^{1} \mathrm{H}-\mathrm{NMR}$ (DMSO- $d_{6}$ ) $\delta$ : $6.87(1 \mathrm{H}, \mathrm{s}, \mathrm{H}-6), 6.39(1 \mathrm{H}, \mathrm{s}, \mathrm{H}-3), 5.58\left(2 \mathrm{H}, \mathrm{s}, \mathrm{NH}_{2}\right), 3.96\left(2 \mathrm{H}, \mathrm{q}, J=6.9 \mathrm{~Hz}, \mathrm{CH}_{3} \mathrm{C}_{2} \mathrm{O}-\right), 3.65$ $\left(3 \mathrm{H}, \mathrm{s},-\mathrm{OCH}_{3}\right), 1.33\left(3 \mathrm{H}, \mathrm{t}, J=6.9 \mathrm{~Hz}, \mathrm{C}_{3} \mathrm{CH}_{2} \mathrm{O}-\right)$; LC-MS: $193.1(\mathrm{M}+\mathrm{H})^{+}$; Anal. Calcd. for $\mathrm{C}_{10} \mathrm{H}_{12} \mathrm{~N}_{2} \mathrm{O}_{2}$ : C 62.49, H 6.29, N 14.57; Found: C 62.50, H 6.30, N 14.58.

2-Amino-5-methoxy-4-pentyloxybenzonitrile (4b): Yield: 50.1\%; mp: 136-137 ${ }^{\circ} \mathrm{C} .{ }^{1} \mathrm{H}-\mathrm{NMR}$ (DMSO$\left.d_{6}\right) \delta: 6.85(1 \mathrm{H}, \mathrm{s}, \mathrm{H}-6), 6.38(1 \mathrm{H}, \mathrm{s}, \mathrm{H}-3), 5.57\left(2 \mathrm{H}, \mathrm{s}, \mathrm{NH}_{2}\right), 3.88(2 \mathrm{H}, \mathrm{t}, J=6.3 \mathrm{~Hz}$, $\left.\mathrm{CH}_{3} \mathrm{CH}_{2} \mathrm{CH}_{2} \mathrm{CH}_{2} \mathrm{CH}_{2} \mathrm{O}-\right), 3.63\left(3 \mathrm{H}, \mathrm{s},-\mathrm{OCH}_{3}\right), 1.70\left(2 \mathrm{H}, \mathrm{m}, \mathrm{CH}_{3} \mathrm{CH}_{2} \mathrm{CH}_{2} \mathrm{C}_{2} \mathrm{CH}_{2} \mathrm{O}-\right), 1.34$ (4H, m, $\left.\mathrm{CH}_{3} \underline{\mathrm{C}}_{2} \mathrm{CH}_{2} \mathrm{CH}_{2} \mathrm{CH}_{2} \mathrm{O}-\right), 0.88\left(3 \mathrm{H}, \mathrm{t}, J=6.9 \mathrm{~Hz}, \mathrm{CH}_{3} \mathrm{CH}_{2} \mathrm{CH}_{2} \mathrm{CH}_{2} \mathrm{CH}_{2} \mathrm{O}-\right)$; LC-MS: $235.1(\mathrm{M}+\mathrm{H})^{+}$; Anal. Calcd. for $\mathrm{C}_{13} \mathrm{H}_{18} \mathrm{~N}_{2} \mathrm{O}_{2}$ : C 66.64, H 7.74, N 11.96; Found: C 66.62, H 7.73, N 11.97.

2-Amino-4-(3-chloropropoxy)-5-methoxybenzonitrile (4c): Yield: 47.2\%; mp: $118-119{ }^{\circ} \mathrm{C} .{ }^{1} \mathrm{H}-\mathrm{NMR}$ $\left(\mathrm{DMSO}_{6}\right) \delta$ : $6.89(1 \mathrm{H}, \mathrm{s}, \mathrm{H}-6), 6.43(1 \mathrm{H}, \mathrm{s}, \mathrm{H}-3), 5.62\left(2 \mathrm{H}, \mathrm{s}, \mathrm{NH}_{2}\right), 4.03(2 \mathrm{H}, \mathrm{t}, J=6.1 \mathrm{~Hz}$, $\left.\mathrm{ClCH}_{2} \mathrm{CH}_{2} \underline{\mathrm{C}}_{2} \mathrm{O}-\right), 3.77\left(2 \mathrm{H}, \mathrm{t}, J=6.4 \mathrm{~Hz}, \mathrm{ClC}_{2} \mathrm{CH}_{2} \mathrm{CH}_{2} \mathrm{O}-\right), 3.65\left(3 \mathrm{H}, \mathrm{s},-\mathrm{OCH}_{3}\right), 2.18(2 \mathrm{H}, \mathrm{m}$, $\left.\mathrm{ClCH}_{2} \mathrm{CH}_{2} \mathrm{CH}_{2} \mathrm{O}-\right)$; LC-MS: $241.1(\mathrm{M}+\mathrm{H})^{+}$; Anal. Calcd. for $\mathrm{C}_{11} \mathrm{H}_{13} \mathrm{ClN}_{2} \mathrm{O}_{2}$ : C 54.89, H 5.44, N 11.64; Found: C 54.88, H 5.45, N 11.63.

General procedure for the synthesis of 7-alkoxy-6-methoxy-4-substituted-1,2,3-benzotriazines 8a-r

Compound 4 (or compound 5 when preparing 8a, $10.0 \mathrm{mmol}$ ) in 10N-hydrochloric acid (30.0 $\mathrm{mL}$ ) was cooled to $0{ }^{\circ} \mathrm{C}$ and diazotized with sodium nitrite $(0.71 \mathrm{~g})$ in water $(10.0 \mathrm{~mL})$. The diazonium solution was neutralized with excess of sodium acetate trihydrate and stirred for $2 \mathrm{~h}$ at $0{ }^{\circ} \mathrm{C}$ with a corresponding substituted aniline $(10.0 \mathrm{mmol})$. The solution was kept overnight at $4{ }^{\circ} \mathrm{C}$, filtered, and washed with water. The crude material was purified on a silica gel column with petroleum ether : ethyl acetate $(\mathrm{v} / \mathrm{v})=10: 1$ to yield a yellow solid $\mathbf{6}$. Compound $\mathbf{6}$ was boiled in $70 \%$ ethanol $(25.0 \mathrm{~mL})$ for 1 
$\mathrm{h}$, then the solution was evaporated under reduced pressure to dryness. Acetic acid $(10.0 \mathrm{~mL})$ was added and the solution was refluxed for $2 \mathrm{~h}$, cooled, poured into water $(100 \mathrm{~mL})$, filtered, and dried to afford 7-alkoxyl-6-methoxy-4-substituted-1,2,3-benzotriazines 8.

4-(4-chloroanilino)-1,2,3-benzotriazine (8a): Yield: 68.9\%; mp: $230{ }^{\circ} \mathrm{C}$. IR (KBr): 3266, 3086, 1621, 1559, 1493, 1424, 1147, $766 \mathrm{~cm}^{-1}$; ${ }^{1} \mathrm{H}-\mathrm{NMR}\left(\mathrm{DMSO}_{6}\right) \delta: 10.02(1 \mathrm{H}, \mathrm{s}, \mathrm{NH}), 8.62(1 \mathrm{H}, \mathrm{d}, \mathrm{J}=8.1$ $\mathrm{Hz}), 8.23(1 \mathrm{H}, \mathrm{d}, \mathrm{J}=8.1 \mathrm{~Hz}), 8.13(1 \mathrm{H}, \mathrm{t}, \mathrm{J}=8.2 \mathrm{~Hz}), 8.05(1 \mathrm{H}, \mathrm{m}), 7.90(2 \mathrm{H}, \mathrm{m}), 7.52$ (2H, m); LCMS: $257.1(\mathrm{M}+\mathrm{H})^{+} ;{ }^{13} \mathrm{C}-\mathrm{NMR}\left(\mathrm{DMSO}_{\mathrm{d}}\right) \delta: 151.02,143.53,137.58,134.73,132.38,128.66,128.06$, 127.47, 124.28, 121.87, 109.04; Anal. Calcd. for $\mathrm{C}_{13} \mathrm{H}_{9} \mathrm{ClN}_{4}$ : C 60.83, H 3.53, N 21.83; Found: C $60.79, \mathrm{H} 3.51, \mathrm{~N} 21.85$.

4-(4-Chloroanilino)-7-ethoxy-6-methoxy-1,2,3-benzotriazine (8b): Yield: $72.1 \%$; mp: $230{ }^{\circ} \mathrm{C}$. IR (KBr): 3296, 2928, 1612, 1560, 1494, 1423, 1291, $818 \mathrm{~cm}^{-1} ;{ }^{1} \mathrm{H}-\mathrm{NMR}$ (DMSO-d 6 ) $\delta: 9.68$ (1H, s, NH), 7.92 (3H, m, H-8, H-2', H-6'), 7.51 (3H, m, H-8, H-3', H-5'), 4.29 (2H, q, J = 6.6 Hz, $\left.\mathrm{CH}_{3} \mathrm{C}_{2}{ }_{2} \mathrm{O}-\right)$, $4.03\left(3 \mathrm{H}, \mathrm{s},-\mathrm{OCH}_{3}\right), 1.44\left(3 \mathrm{H}, \mathrm{t}, J=6.9 \mathrm{~Hz}, \mathrm{CH}_{3} \mathrm{CH}_{2} \mathrm{O}-\right)$; LC-MS: $331.1(\mathrm{M}+\mathrm{H})^{+} ;{ }^{13} \mathrm{C}-\mathrm{NMR}$ (DMSO$\left.d_{6}\right) \delta: 154.22(\mathrm{C}-7), 153.27$ (C-6), 150.12 (C-10), 141.65 (C-9), 137.95 (C-1'), 128.57, 127.48, 123.95, 106.78 (C-5), 103.84 (C-4), 100.09 (C-8), $64.74\left(\mathrm{CH}_{3} \underline{\mathrm{CH}}_{2} \mathrm{O}-\right), 56.73\left(-\mathrm{OCH}_{3}\right), 14.42\left(\underline{\mathrm{CH}}_{3} \mathrm{CH}_{2} \mathrm{O}-\right)$; Anal. Calcd. for $\mathrm{C}_{16} \mathrm{H}_{15} \mathrm{ClN}_{4} \mathrm{O}_{2}$ : C 58.10, H 4.57, N 16.94; Found: C 58.01, H 4.56, N 16.96.

7-Ethoxy-6-methoxy-4-(4-methylanilino)-1,2,3-benzotriazine (8c): Yield: 73.2\%; mp: 249-251 ${ }^{\circ} \mathrm{C}$. IR (KBr): 33381, 2980, 1614, 1512, 1426, 1283, 1244, 1103, 856, $816 \mathrm{~cm}^{-1} ;{ }^{1} \mathrm{H}-\mathrm{NMR}$ (DMSO-d $\left.{ }_{6}\right) \delta: 9.50$ (s, 1H, NH), 7.90 (s, 1H, H-8), 7.70 (d, 2H, J = 8.2 Hz, ArH-2'H, 6'H), 7.53 (s, 1H, H-5), 7.25 (d, 2H, $\left.J=8.2 \mathrm{~Hz}, \mathrm{ArH}-3^{\prime} \mathrm{H}, 5^{\prime} \mathrm{H}\right), 4.29$ (q, $\left.2 \mathrm{H}, J=6.9 \mathrm{~Hz}, \mathrm{CH}_{3} \mathrm{C}_{2} \mathrm{O}-\right), 4.02$ (s, 3H, $\left.\mathrm{C}_{3} \mathrm{O}-\right), 2.34$ (s, 3H, ArH-4' $\underline{H}_{3}$ ), 1.44 (t, $3 \mathrm{H}, J=6.8 \mathrm{~Hz}, \underline{\mathrm{C}}_{3} \mathrm{CH}_{2} \mathrm{O}-$ ); LC-MS: $311.2(\mathrm{M}+\mathrm{H})^{+} ;{ }^{13} \mathrm{C}-\mathrm{NMR}$ (DMSO- $\left.d_{6}\right) \delta$ : $154.16,153.19,150.30,141.62,138.86,128.72,124.04,122.70,106.77,103.82,100.12,64.73,56.72$, 20.89, 14.46; Anal. Calcd. for $\mathrm{C}_{17} \mathrm{H}_{18} \mathrm{~N}_{4} \mathrm{O}_{2}$ : C 65.79, H 5.85, N 18.05; Found: C 65.68, H 5.81, N 18.07 .

4-(3-Chloro-4-fluoroanilino)-7-ethoxy-6-methoxy-1,2,3-benzotriazine (8d): Yield: 64.1\%; mp: 248$250{ }^{\circ} \mathrm{C}$. IR (KBr): $3288,1609,1554,1500,1417,1292,1237,1222,1106 \mathrm{~cm}^{-1}$; ${ }^{1} \mathrm{H}-\mathrm{NMR}$ (DMSO-d $d_{6}$ ) $\delta: 9.66$ (s, 1H, NH), 8.17 (m, 1H, ArH-2'H), 7.87 (s, 1H, H-8), 7.82 (m, 1H, ArH-5'H), 7.58 (s, 1H, H5), 7.51 (d, $1 \mathrm{H}, J=9 \mathrm{~Hz}, \mathrm{ArH}-6$ 'H), 4.31 (q, $2 \mathrm{H}, J=6.9 \mathrm{~Hz}, \mathrm{CH}_{3} \underline{\mathrm{C}}_{2} \mathrm{O}-$ ), 4.03 (s, 3H, $\mathrm{CH}_{3} \mathrm{O}-$ ), 1.44 (t, $3 \mathrm{H}, J=6.9 \mathrm{~Hz}, \mathrm{CH}_{3} \mathrm{CH}_{2} \mathrm{O}-$ ); LC-MS: $349.2(\mathrm{M}+\mathrm{H})^{+} ;{ }^{13} \mathrm{C}-\mathrm{NMR}\left(\mathrm{DMSO}-d_{6}\right) \delta: 154.43,154.29,153.62$, $152.10,150.35,141.80,136.65,124.10,123.00,122.90,119.55,117.10,116.80,107.15,104.13$, 100.28, 64.69, 56.65, 14.46; Anal. Calcd. for $\mathrm{C}_{16} \mathrm{H}_{14} \mathrm{ClFN}_{4} \mathrm{O}_{2}$ : C 55.10, H 4.05, N 16.06; Found: C 55.00, H 4.07, N 16.04 .

4-(4-Chloroanilino)-6-methoxy-7-pentyloxy-1,2,3-benzotriazine (8e): Yield: 69.3\%; mp: $213{ }^{\circ} \mathrm{C}$. IR (KBr): 3378, 2954, 1612, 1562, 1507, 1426, 1245, $817 \mathrm{~cm}^{-1} ;{ }^{1} \mathrm{H}-\mathrm{NMR}$ (DMSO-d 6 ) $\delta: 9.63$ (1H, s, NH), 7.91 (3H, m, H-8, H-2', H-6'), 7.53 (3H, m, H-8, H-3', H-5'), 4.24 (2H, t, J = 6.0 Hz, $\left.\mathrm{CH}_{3} \mathrm{CH}_{2} \mathrm{CH}_{2} \mathrm{CH}_{2} \mathrm{CH}_{2} \mathrm{O}-\right), 4.03\left(3 \mathrm{H}, \mathrm{s},-\mathrm{OCH}_{3}\right), 1.82\left(2 \mathrm{H}, \mathrm{m}, \mathrm{CH}_{3} \mathrm{CH}_{2} \mathrm{CH}_{2} \mathrm{C}_{2} \mathrm{CH}_{2} \mathrm{O}-\right), 1.40$ (4H, m, $\left.\mathrm{CH}_{3} \underline{\mathrm{C}}_{2} \mathrm{C}_{2} \mathrm{CH}_{2} \mathrm{CH}_{2} \mathrm{O}-\right), 0.92\left(3 \mathrm{H}, \mathrm{t}, J=6.0 \mathrm{~Hz}, \mathrm{C}_{3} \mathrm{CH}_{2} \mathrm{CH}_{2} \mathrm{CH}_{2} \mathrm{CH}_{2} \mathrm{O}\right)$; LC-MS: $373.2(\mathrm{M}+\mathrm{H})^{+}$; 
${ }^{13}$ C-NMR (DMSO-d ${ }_{6}$ ) $\delta: 154.31$ (C-7), 153.27 (C-6), 150.30 (C-10), 141.63 (C-9), 138.88 (C-1'), 128.73, 127.40, 123.91, 106.72 (C-5), 103.82 (C-4), 100.05 (C-8), $68.98\left(\mathrm{CH}_{3} \mathrm{CH}_{2} \mathrm{CH}_{2} \mathrm{CH}_{2} \mathrm{CH}_{2} \mathrm{O}-\right)$, $56.79 \quad\left(-\mathrm{OCH}_{3}\right), \quad 28.17 \quad\left(\mathrm{CH}_{3} \mathrm{CH}_{2} \mathrm{CH}_{2} \mathrm{CH}_{2} \mathrm{CH}_{2} \mathrm{O}-\right), \quad 27.78 \quad\left(\mathrm{CH}_{3} \mathrm{CH}_{2} \mathrm{CH}_{2} \mathrm{CH}_{2} \mathrm{CH}_{2} \mathrm{O}-\right), \quad 21.98$

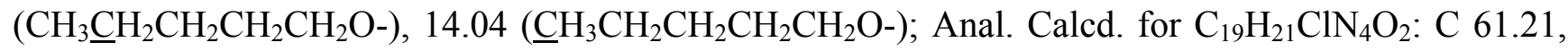
H 5.68, N 15.03; Found: C 61.11, H 5.64, N 14.99.

6-Methoxy-7-pentyloxy-4-(3-trifluoromethoxyanilino)-1,2,3-benzotriazine (8f): Yield: 73.1\%; mp: 181-183 ${ }^{\circ} \mathrm{C}$. IR (KBr): 3421, 2931, 1613, 1508, 1446, 1258, 1216, 1163, 1105, 845, $784 \mathrm{~cm}^{-1} ;{ }^{1} \mathrm{H}-$ NMR (DMSO-d $\left.)_{6}\right) \delta: 9.72$ (s, 1H, NH), 8.04 (s, 1H, ArH-2'H), 7.92 (d, 1H, J = 8.9 Hz, ArH-4'H), 7.91 (s, 1H, H-8), 7.60 (s, 1H, H-5), 7.56 (t, 2H, J = 8.6 Hz, ArH-5'H), 7.14 (d, 1H, J = 8.7 Hz, ArH-6'H), $4.24\left(\mathrm{t}, 2 \mathrm{H}, \quad J=6.3 \mathrm{~Hz}, \mathrm{CH}_{3} \mathrm{CH}_{2} \mathrm{CH}_{2} \mathrm{CH}_{2} \underline{\mathrm{CH}}_{2} \mathrm{O}-\right), 4.05$ (s, 3H, $\left.\mathrm{CH}_{3} \mathrm{O}-\right), 1.83(\mathrm{~m}, 2 \mathrm{H}$, $\left.\mathrm{CH}_{3} \mathrm{CH}_{2} \mathrm{CH}_{2} \underline{\mathrm{C}}_{2} \mathrm{CH}_{2} \mathrm{O}-\right), 1.42\left(\mathrm{~m}, 4 \mathrm{H}, \mathrm{CH}_{3} \underline{\mathrm{C}}_{2} \mathrm{C}_{2} \mathrm{CH}_{2} \mathrm{CH}_{2} \mathrm{O}-\right), 0.92 \quad(\mathrm{t}, 3 \mathrm{H}, \quad J=6.9 \mathrm{~Hz}$, $\mathrm{CH}_{3} \mathrm{CH}_{2} \mathrm{CH}_{2} \mathrm{CH}_{2} \mathrm{CH}_{2} \mathrm{O}-$ ); LC-MS: $423.2(\mathrm{M}+\mathrm{H})^{+}$; ${ }^{13} \mathrm{C}-\mathrm{NMR}$ (DMSO-d $)_{6}$ ) : $154.23,153.52,150.28$, 148.76, 141.90, 141.06, 130.41, 124.25, 121.80, 118.10, 115.20, 114.04, 106.92, 104.11, 100.19, 68.98, 56.79, 28.17, 27.78, 21.98, 14.04; Anal. Calcd. for $\mathrm{C}_{20} \mathrm{H}_{21} \mathrm{~F}_{3} \mathrm{~N}_{4} \mathrm{O}_{3}$ : C 56.87, H 5.01, N 13.26; Found: C 56.81, H 5.00, N 13.23.

6-Methoxy-7-pentyloxy-4-(4-trifluoromethoxyanilino)-1,2,3-benzotriazine (8g): Yield: 70.2\%; mp: 230-232 ${ }^{\circ} \mathrm{C}$. IR (KBr): 3426, 2959, 1615, 1510, 1428, 1247, 1200, 1165, 1102, 850, $786 \mathrm{~cm}^{-1}$; ${ }^{1} \mathrm{H}-$ NMR (DMSO-d $)_{6}$ ) : 9.69 (s, 1H, NH), 7.98 (d, 2H, J=9.0 Hz, ArH-3'H, 5'H), 7.90 (s, 1H, H-8), 7.58 (s, 1H, H-5), 7.46 (d, 2H, J = 8.7 Hz, ArH-2' $\mathrm{H}, 6$ ' $\mathrm{H}$ ), 4.24 (t, 2H, J = 6.3 Hz, $\mathrm{CH}_{3} \mathrm{CH}_{2} \mathrm{CH}_{2} \mathrm{CH}_{2} \mathrm{CH}_{2} \mathrm{O}-$ ), 4.04 (s, 3H, $\left.\underline{\mathrm{H}}_{3} \mathrm{O}-\right), 1.83$ (m, $2 \mathrm{H}, \mathrm{CH}_{3} \mathrm{CH}_{2} \mathrm{CH}_{2} \mathrm{CH}_{2} \mathrm{CH}_{2} \mathrm{O}-$ ), 1.42 (m, 4H, $\mathrm{CH}_{3} \underline{\mathrm{C}}_{2} \mathrm{C}_{2} \mathrm{CH}_{2} \mathrm{CH}_{2} \mathrm{O}-$ ), $0.92\left(\mathrm{t}, 3 \mathrm{H}, J=6.9 \mathrm{~Hz}, \mathrm{CH}_{3} \mathrm{CH}_{2} \mathrm{CH}_{2} \mathrm{CH}_{2} \mathrm{CH}_{2} \mathrm{O}-\right.$ ); LC-MS: $423.2(\mathrm{M}+\mathrm{H})^{+} ;{ }^{13} \mathrm{C}-\mathrm{NMR}$ (DMSO- $\left.d_{6}\right) \delta$ : $154.31,153.27,150.30,144.05,141.54,137.91,125.24,123.93,122.14,121.45,106.86,103.83$, 100.08, 68.97, 56.76, 28.17, 27.76, 21.97, 14.04; Anal. Calcd. for $\mathrm{C}_{20} \mathrm{H}_{21} \mathrm{~F}_{3} \mathrm{~N}_{4} \mathrm{O}_{3}$ : C 56.87, H 5.01, N 13.26; Found: C 56.88, H 5.03, N 13.27.

7-(3-Chloropropoxy)-4-(3,5-dichloroanilino)-6-methoxy-1,2,3-benzotriazine (8h): Yield: 72.9\%; mp: 110-112 ${ }^{\circ} \mathrm{C}$. IR (KBr): 3430, 2919, 1620, 1508, 1423, 1289, $849 \mathrm{~cm}^{-1} ;{ }^{1} \mathrm{H}-\mathrm{NMR}$ (DMSO-d (D) $\mathbf{9} .74$ $(1 \mathrm{H}, \mathrm{s}, \mathrm{NH}), 8.10$ (2H, d, J = 1.77 Hz, H-2', H-6'), $7.91(1 \mathrm{H}, \mathrm{s}, \mathrm{H}-8), 7.68$ (1H, s, H-5), 7.37 (1H, s, H4'), 4.39 (2H, t, $\left.J=6.15 \mathrm{~Hz}, \mathrm{ClCH}_{2} \mathrm{CH}_{2} \mathrm{CH}_{2} \mathrm{O}-\right), 4.06\left(3 \mathrm{H}, \mathrm{s},-\mathrm{OCH}_{3}\right), 3.84(2 \mathrm{H}, \mathrm{t}, J=6.5 \mathrm{~Hz}$, $\left.\mathrm{ClCH}_{2} \mathrm{CH}_{2} \mathrm{CH}_{2} \mathrm{O}-\right), 2.30\left(2 \mathrm{H}, \mathrm{m}, \mathrm{ClCH}_{2} \underline{\mathrm{C}}_{2} \mathrm{CH}_{2} \mathrm{O}-\right.$ ); LC-MS: $413.0(\mathrm{M}+\mathrm{H})^{+} ;{ }^{13} \mathrm{C}-\mathrm{NMR}$ (DMSO-d $\left.{ }_{6}\right) \delta$ : 154.57 (C-7), 153.92 (C-6), 150.31 (C-10), 142.11 (C-9), 141.94, 134.28, 122.82, 120.06, 107.51 (C5), 104.54 (C-4), 100.44 (C-8), $66.29\left(\mathrm{ClCH}_{2} \mathrm{CH}_{2} \underline{\mathrm{CH}}_{2} \mathrm{O}-\right), 57.26\left(-\mathrm{OCH}_{3}\right), 42.19\left(\mathrm{Cl}^{\mathrm{CH}}{ }_{2} \mathrm{CH}_{2} \mathrm{CH}_{2} \mathrm{O}-\right)$, $31.84\left(\mathrm{ClCH}_{2} \mathrm{CH}_{2} \mathrm{CH}_{2} \mathrm{O}-\right)$; Anal. Calcd. for $\mathrm{C}_{17} \mathrm{H}_{15} \mathrm{Cl}_{3} \mathrm{~N}_{4} \mathrm{O}_{2}$ : C 49.36, H 3.65, N 13.54; Found: $\mathrm{C} 49.28$, H 3.66, N 13.56 .

7-(3-Chloropropoxy)-4-(3,4-dichlorophenyl)-6-methoxy-1,2,3-benzotriazine (8i): Yield: 72.4\%; mp: 120-122 ${ }^{\circ} \mathrm{C}$. IR (KBr): 3424, 1616, 1510, 1426, 1281, $848 \mathrm{~cm}^{-1} ;{ }^{1} \mathrm{H}-\mathrm{NMR}$ (DMSO-d 6 ) $\delta: 9.74$ (1H, s, NH), 8.31 (1H, d, J = 2.31 Hz, H-2'), 7.93 (2H, m, H-8, H-6'), 7.71 (1H, m, H-5'), 7.67 (1H, s, H-5), $4.38\left(2 \mathrm{H}, \mathrm{t}, J=6.0 \mathrm{~Hz}, \mathrm{ClCH}_{2} \mathrm{CH}_{2} \mathrm{CH}_{2} \mathrm{O}-\right), 4.05\left(3 \mathrm{H}, \mathrm{s},-\mathrm{OCH}_{3}\right), 3.84(2 \mathrm{H}, \mathrm{t}, J=6.4 \mathrm{~Hz}$, 
$\left.\mathrm{ClC}_{2} \mathrm{CH}_{2} \mathrm{CH}_{2} \mathrm{O}-\right), 2.30$ (2H, m, $\mathrm{ClCH}_{2} \underline{\mathrm{C}}_{2} \mathrm{CH}_{2} \mathrm{O}-$ ); LC-MS: $413.0(\mathrm{M}+\mathrm{H})^{+} ;{ }^{13} \mathrm{C}-\mathrm{NMR}$ (DMSO-d $\left.{ }_{6}\right) \delta$ : 154.11 (C-7), 153.43 (C-6), 149.95 (C-10), 141.66 (C-9), 139.23, 130.84, 130.51, 125.02, 123.14, 121.90, 107.10 (C-5), 104.11 (C-4), 100.08 (C-8), $65.86\left(\mathrm{ClCH}_{2} \mathrm{CH}_{2} \mathrm{CH}_{2} \mathrm{O}-\right), 56.85\left(-\mathrm{OCH}_{3}\right), 41.87$ $\left(\mathrm{Cl}_{\mathrm{CH}} \mathrm{CH}_{2} \mathrm{CH}_{2} \mathrm{O}-\right), 31.46\left(\mathrm{ClCH}_{2} \mathrm{CH}_{2} \mathrm{CH}_{2} \mathrm{O}-\right)$; Anal. Calcd. for $\mathrm{C}_{17} \mathrm{H}_{15} \mathrm{Cl}_{3} \mathrm{~N}_{4} \mathrm{O}_{2}: \mathrm{C}$ 49.36, $\mathrm{H} 3.65, \mathrm{~N}$ 13.54; Found: C 49.31, H 3.66, N 13.56.

4-(4-Chloroanilino)-7-(3-chloropropoxy)-6-methoxy-1,2,3-benzotriazine (8j): Yield: 67.9\%; mp: 253 ${ }^{\circ} \mathrm{C}$. IR (KBr): 3425, 2925, 1616, 1561, 1495, 1424, 1245, $839 \mathrm{~cm}^{-1} ;{ }^{1} \mathrm{H}-\mathrm{NMR}\left(\mathrm{DMSO}-d_{6}\right) \delta: 9.66(1 \mathrm{H}$, s, NH), 7.91 (3H, m, H-8, H-2', H-6'), 7.62 (1H, s, H-5), 7.50 (2H, d, J = 8.8 Hz, H-3', H-5'), 4.37 $\left(2 \mathrm{H}, \mathrm{t}, J=6.0 \mathrm{~Hz}, \mathrm{ClCH}_{2} \mathrm{CH}_{2} \mathrm{CH}_{2} \mathrm{O}-\right), 4.04\left(3 \mathrm{H}, \mathrm{s},-\mathrm{OCH}_{3}\right), 3.84\left(2 \mathrm{H}, \mathrm{t}, J=6.4 \mathrm{~Hz}, \mathrm{ClC}_{2} \mathrm{CH}_{2} \mathrm{CH}_{2} \mathrm{O}-\right)$, $2.29\left(2 \mathrm{H}, \mathrm{m}, \mathrm{ClCH}_{2} \mathrm{CH}_{2} \mathrm{CH}_{2} \mathrm{O}-\right)$; LC-MS: $379.0(\mathrm{M}+\mathrm{H})^{+} ;{ }^{13} \mathrm{C}-\mathrm{NMR}$ (DMSO-d $\left.)_{6}\right) \delta: 153.99$ (C-7), 153.29 (C-6), 150.12 (C-10), 141.57 (C-9), 137.91 (C-1'), 128.59, 127.54, 123.99, 107.07 (C-5), $104.07(\mathrm{C}-4), 100.23(\mathrm{C}-8), 65.82\left(\mathrm{ClCH}_{2} \mathrm{CH}_{2} \mathrm{CH}_{2} \mathrm{O}-\right), 56.82\left(-\mathrm{OCH}_{3}\right), 41.87\left(\mathrm{Cl}^{\mathrm{CH}}{ }_{2} \mathrm{CH}_{2} \mathrm{CH}_{2} \mathrm{O}-\right)$, $31.47\left(\mathrm{ClCH}_{2} \mathrm{CH}_{2} \mathrm{CH}_{2} \mathrm{O}-\right)$; Anal. Calcd. for $\mathrm{C}_{17} \mathrm{H}_{16} \mathrm{Cl}_{2} \mathrm{~N}_{4} \mathrm{O}_{2}$ : C 53.84, H 4.25, N 14.77; Found: C 53.79, H 4.24, N 14.71 .

7-(3-Chloropropoxy)-6-methoxy-4-(4-methylanilino)-1,2,3-benzotriazine (8k): Yield: 70.1\%; mp: 247 ${ }^{\circ} \mathrm{C}$. IR (KBr): 3420, 2924, 1615, 1513, 1425, 1282, 1242, $859 \mathrm{~cm}^{-1} ;{ }^{1} \mathrm{H}-\mathrm{NMR}\left(\mathrm{DMSO}-d_{6}\right) \delta: 9.55(1 \mathrm{H}$, s, NH), 7.92 (1H, s, H-8), 7.69 (2H, d, J = 8.4 Hz, H-2', H-6'), 7.59 (1H, s, H-5), 7.25 (2H, d, J= 8.4 Hz, H-3', H-5'), 4.37 (2H, t, $\left.J=6.0 \mathrm{~Hz}, \mathrm{ClCH}_{2} \mathrm{CH}_{2} \underline{\mathrm{C}}_{2} \mathrm{O}-\right), 4.03\left(3 \mathrm{H}, \mathrm{s},-\mathrm{OCH}_{3}\right), 3.84$ (2H, t, $J=6.3$ $\left.\mathrm{Hz}, \mathrm{ClCH}_{2} \mathrm{CH}_{2} \mathrm{CH}_{2} \mathrm{O}-\right), 2.34\left(3 \mathrm{H}, \mathrm{s},-\mathrm{CH}_{3}\right), 2.29\left(2 \mathrm{H}, \mathrm{m}, \mathrm{ClCH}_{2} \mathrm{C}_{2} \mathrm{CH}_{2} \mathrm{O}-\right)$; LC-MS: $359.1(\mathrm{M}+\mathrm{H})^{+}$; ${ }^{13} \mathrm{C}-\mathrm{NMR}\left(\mathrm{DMSO}-d_{6}\right.$ ) $\delta$ : 154.23 (C-7), 153.51 (C-6), 150.62 (C-10), 141.59 (C-9), 136.43 (C-1'), 133.64, 129.48, 123.22, 107.28 (C-5), 104.42 (C-4), 100.86 (C-8), $66.14\left(\mathrm{ClCH}_{2} \mathrm{CH}_{2} \underline{\mathrm{CH}}_{2} \mathrm{O}-\right)$, 57.22 ($\left.\mathrm{OCH}_{3}\right), 42.24\left(\mathrm{ClCH}_{2} \mathrm{CH}_{2} \mathrm{CH}_{2} \mathrm{O}-\right), 31.84\left(\mathrm{ClCH}_{2} \underline{\mathrm{CH}}_{2} \mathrm{CH}_{2} \mathrm{O}-\right), 20.99\left(\mathrm{Ph}_{-} \underline{\mathrm{CH}}_{3}\right) ;$ Anal. Calcd. for $\mathrm{C}_{18} \mathrm{H}_{19} \mathrm{ClN}_{4} \mathrm{O}_{2}$ : C 60.25, H 5.34, N 15.61; Found: C 60.28, H 5.33, N 15.56.

7-(3-Chloropropoxy)-4-(4-fluoroanilino)-6-methoxy-1,2,3-benzotriazine (8I): Yield: 71.2\%; mp: 166 ${ }^{\circ} \mathrm{C}$. IR (KBr): 3437, 1620, 1510, 1428, 1284, $842 \mathrm{~cm}^{-1} ;{ }^{1} \mathrm{H}-\mathrm{NMR}$ (DMSO-d 6 ) $\delta: 9.63$ (1H, s, NH), 7.91 (1H, s, H-8), 7.84 (2H, m, H-2', H-6'), 7.61 (1H, s, H-5), 7.29 (2H, t, J=8.7 Hz, H-3', H-5'), 4.37 $\left(2 \mathrm{H}, \mathrm{t}, J=6.0 \mathrm{~Hz}, \mathrm{ClCH}_{2} \mathrm{CH}_{2} \mathrm{C}_{2} \mathrm{O}-\right), 4.03\left(3 \mathrm{H}, \mathrm{s},-\mathrm{OCH}_{3}\right), 3.84\left(2 \mathrm{H}, \mathrm{t}, J=6.4 \mathrm{~Hz}, \mathrm{ClC}_{2} \mathrm{CH}_{2} \mathrm{CH}_{2} \mathrm{O}-\right)$, $2.29\left(2 \mathrm{H}, \mathrm{m}, \mathrm{ClCH}_{2} \mathrm{CH}_{2} \mathrm{CH}_{2} \mathrm{O}-\right)$; LC-MS: $363.1(\mathrm{M}+\mathrm{H})^{+} ;{ }^{13} \mathrm{C}-\mathrm{NMR}$ (DMSO-d $\left.\mathrm{d}_{6}\right) \delta: 160.67,157.48$, 154.28 (C-7), 153.56 (C-6), 150.64 (C-10), 141.79 (C-9), 135.46 (C-1'), 125.15, 125.04, 115.79, 115.50, 107.40 (C-5), 104.29 (C-4), 100.67 (C-8), $66.18\left(\mathrm{ClCH}_{2} \mathrm{CH}_{2} \mathrm{CH}_{2} \mathrm{O}-\right), 57.17\left(-\mathrm{OCH}_{3}\right), 42.22$ $\left(\mathrm{ClCH}_{2} \mathrm{CH}_{2} \mathrm{CH}_{2} \mathrm{O}-\right), 31.86\left(\mathrm{ClCH}_{2} \mathrm{CH}_{2} \mathrm{CH}_{2} \mathrm{O}-\right)$; Anal. Calcd. for $\mathrm{C}_{17} \mathrm{H}_{16} \mathrm{ClFN}_{4} \mathrm{O}_{2}: \mathrm{C} 56.28, \mathrm{H} 4.45, \mathrm{~N}$ 15.44; Found: C 56.20, H 4.43, N 15.56.

4-(3-Chloro-4-fluoroanilino)-7-(3-chloropropoxy)-6-methoxy-1,2,3-benzotriazine (8m): Yield: 77.1\%; mp: $138-139{ }^{\circ} \mathrm{C}$. IR (KBr): $3314,2923,1616,1571,1511,1427,1285,849 \mathrm{~cm}^{-1}$; ${ }^{1} \mathrm{H}-\mathrm{NMR}$ (DMSO-d $d_{6}$ )

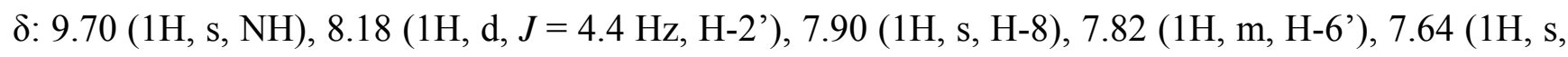
H-5), $7.51\left(1 \mathrm{H}, \mathrm{t}, J=9.1 \mathrm{~Hz}, \mathrm{H}-5\right.$ '), $4.38\left(2 \mathrm{H}, \mathrm{t}, J=5.9 \mathrm{~Hz}, \mathrm{ClCH}_{2} \mathrm{CH}_{2} \mathrm{C}_{2} \mathrm{O}-\right), 4.04$ (3H, s, $\left.-\mathrm{OCH}_{3}\right)$, $3.84\left(2 \mathrm{H}, \mathrm{t}, J=6.4 \mathrm{~Hz}, \mathrm{ClC}_{2} \mathrm{CH}_{2} \mathrm{CH}_{2} \mathrm{O}-\right), 2.29\left(2 \mathrm{H}, \mathrm{m}, \mathrm{ClCH}_{2} \underline{\mathrm{C}}_{2} \mathrm{CH}_{2} \mathrm{O}-\right)$; LC-MS: $397.0(\mathrm{M}+\mathrm{H})^{+}$; ${ }^{13} \mathrm{C}-\mathrm{NMR}\left(\mathrm{DMSO}-d_{6}\right) \delta$ : 155.47 (C-4'), 154.32 (C-7), 153.64 (C-6), 152.25 (C-4'), 150.32 (C-10), 
141.81 (C-9), 136.57 (C-1'), 124.15 (C-2'), 122.93 (C-6'), 122.84 (C-6'), 119.47 (C-6'), 117.14 (C5'), 116.85 (C-5'), 107.33 (C-5), 104.28 (C-4), 100.56 (C-8), $66.19\left(\mathrm{ClCH}_{2} \mathrm{CH}_{2} \mathrm{CH}_{2} \mathrm{O}-\right), 57.21$ ($\left.\mathrm{OCH}_{3}\right), 42.18\left(\mathrm{ClCH}_{2} \mathrm{CH}_{2} \mathrm{CH}_{2} \mathrm{O}-\right), 31.86\left(\mathrm{ClCH}_{2} \mathrm{CH}_{2} \mathrm{CH}_{2} \mathrm{O}-\right)$; Anal. Calcd. for $\mathrm{C}_{17} \mathrm{H}_{15} \mathrm{Cl}_{2} \mathrm{FN}_{4} \mathrm{O}_{2}$ : C 51.40, H 3.81, N 14.10; Found: C 51.41, H 3.85, N 14.08.

7-(3-Chloropropoxy)-6-methoxy-4-(3-trifluoromethoxyanilino)-1,2,3-benzotriazine $\quad(\mathbf{8 n})$ : $\quad$ Yield: 65.3\%; mp: $154-155{ }^{\circ} \mathrm{C}$. IR (KBr): $3427,1615,1572,1511,1448,1256,854 \mathrm{~cm}^{-1}$; ${ }^{1} \mathrm{H}-\mathrm{NMR}$ (DMSO$\left.\mathrm{d}_{6}\right) \delta: 9.75(1 \mathrm{H}, \mathrm{s}, \mathrm{NH}), 8.05\left(1 \mathrm{H}, \mathrm{s}, \mathrm{H}-2^{\prime}\right), 7.93(2 \mathrm{H}, \mathrm{s}, \mathrm{H}-8, \mathrm{H}-6$ ') 7.65 (1H, s, H-5), 7.59 (1H, t, $J=$ $8.2 \mathrm{~Hz}, \mathrm{H}-5$ '), $7.15\left(1 \mathrm{H}, \mathrm{d}, J=7.9 \mathrm{~Hz}, \mathrm{H}-4\right.$ '), $4.38\left(2 \mathrm{H}, \mathrm{t}, J=5.9 \mathrm{~Hz}, \mathrm{ClCH}_{2} \mathrm{CH}_{2} \mathrm{C}_{2} \mathrm{O}-\right), 4.06$ (3H, s, $\mathrm{OCH}_{3}$ ), $3.84\left(2 \mathrm{H}, \mathrm{t}, J=6.4 \mathrm{~Hz}, \mathrm{ClC}_{2} \mathrm{CH}_{2} \mathrm{CH}_{2} \mathrm{O}-\right), 2.29$ (2H, m, $\left.\mathrm{ClCH}_{2} \mathrm{CH}_{2} \mathrm{CH}_{2} \mathrm{O}-\right)$; LC-MS: 429.1 $(\mathrm{M}+\mathrm{H}){ }^{+} ;{ }^{13} \mathrm{C}-\mathrm{NMR}$ (DMSO-d $)$ ) $\delta: 154.34$ (C-7), 153.65 (C-6), 150.40 (C-10), 148.82, 141.96 (C-9), 141.12 (C-1'), 130.54, 124.05, 122.30, 118.90, 115.91, 114.64, 107.32 (C-5), 104.41 (C-4), 100.46 (C8), $66.15\left(\mathrm{ClCH}_{2} \mathrm{CH}_{2} \underline{\mathrm{CH}}_{2} \mathrm{O}-\right), 57.17\left(-\mathrm{OCH}_{3}\right), 42.17\left(\mathrm{ClCH}_{2} \mathrm{CH}_{2} \mathrm{CH}_{2} \mathrm{O}-\right), 31.82\left(\mathrm{ClCH}_{2} \underline{\mathrm{CH}}_{2} \mathrm{CH}_{2} \mathrm{O}-\right)$; Anal. Calcd. for $\mathrm{C}_{18} \mathrm{H}_{16} \mathrm{ClF}_{3} \mathrm{~N}_{4} \mathrm{O}_{3}$ : C 50.42, H 3.76, N 13.07; Found: C 50.37, H 3.78, N 13.06.

7-(3-Chloropropoxy)-6-methoxy-4-(4-trifluoromethoxyanilino)-1,2,3-benzotriazine (8o): Yield: 63.0\%; mp: $150{ }^{\circ} \mathrm{C}$. IR (KBr): 3444, 1618, 1574, 1510, 1429, 1247, $852 \mathrm{~cm}^{-1} ;{ }^{1} \mathrm{H}-\mathrm{NMR}$ (DMSO-d $\left.\mathrm{d}_{6}\right) \delta: 9.68$ $(1 \mathrm{H}, \mathrm{s}, \mathrm{NH}), 7.93$ (2H, d, J = 9.0 Hz, H-2', H-6'), 7.88 (1H, s, H-8), 7.59 (1H, s, H-5), 7.40 (2H, d, J = $8.7 \mathrm{~Hz}, \mathrm{H}-3$ ', H-5'), 4.33 (2H, t, $\left.J=5.9 \mathrm{~Hz}, \mathrm{ClCH}_{2} \mathrm{CH}_{2} \mathrm{CH}_{2} \mathrm{O}-\right), 4.00\left(3 \mathrm{H}, \mathrm{s},-\mathrm{OCH}_{3}\right), 3.79(2 \mathrm{H}, \mathrm{t}, J=$ $\left.6.6 \mathrm{~Hz}, \mathrm{ClC}_{2} \mathrm{CH}_{2} \mathrm{CH}_{2} \mathrm{O}-\right), 2.25\left(2 \mathrm{H}, \mathrm{m}, \mathrm{ClCH}_{2} \underline{\mathrm{C}}_{2} \mathrm{CH}_{2} \mathrm{O}-\right)$; LC-MS: $429.1(\mathrm{M}+\mathrm{H})^{+} ;{ }^{13} \mathrm{C}-\mathrm{NMR}$ $\left(\mathrm{DMSO}_{6}\right) \delta$ : 154.41 (C-7), 153.70 (C-6), 150.54 (C-10), 144.48, 141.97 (C-9), 138.51 (C-1'), 125.64, 124.23, 122.34, 121.79, 107.46 (C-5), 104.43 (C-4), 100.68 (C-8), $66.23\left(\mathrm{ClCH}_{2} \mathrm{CH}_{2} \underline{\mathrm{CH}}_{2} \mathrm{O}-\right)$, $57.22\left(-\mathrm{OCH}_{3}\right), \quad 42.21 \quad\left(\mathrm{Cl}^{\mathrm{C}} \mathrm{H}_{2} \mathrm{CH}_{2} \mathrm{CH}_{2} \mathrm{O}-\right), \quad 31.85 \quad\left(\mathrm{ClCH}_{2} \underline{\mathrm{CH}}_{2} \mathrm{CH}_{2} \mathrm{O}-\right) ; \quad$ Anal. Calcd. for $\mathrm{C}_{18} \mathrm{H}_{16} \mathrm{ClF}_{3} \mathrm{~N}_{4} \mathrm{O}_{3}$ : C 50.42, H 3.76, N 13.07; Found: C 50.39, H 3.75, N 13.04.

7-(3-Chloropropoxy)-4-(4-fluoro-3-trifluoromethylanilino)-6-methoxy-1,2,3-benzotriazine (8p): Yield: 71.1\%; mp: $150{ }^{\circ} \mathrm{C}$. IR (KBr): 3452, 2920, 1614, 1508, 1432, 1290, $1129 \mathrm{~cm}^{-1}$; ${ }^{1} \mathrm{H}-\mathrm{NMR}$ (DMSO-d $d_{6}$ )

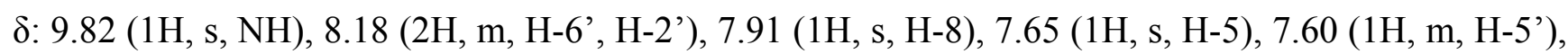
$4.38\left(2 \mathrm{H}, \mathrm{t}, J=6.0 \mathrm{~Hz}, \mathrm{ClCH}_{2} \mathrm{CH}_{2} \mathrm{CH}_{2} \mathrm{O}-\right), 4.05\left(3 \mathrm{H}, \mathrm{s},-\mathrm{OCH}_{3}\right), 3.84(2 \mathrm{H}, \mathrm{t}, J=6.3 \mathrm{~Hz}$, $\left.\mathrm{ClCH}_{2} \mathrm{CH}_{2} \mathrm{CH}_{2} \mathrm{O}-\right), 2.30\left(2 \mathrm{H}, \mathrm{m}, \mathrm{ClCH}_{2} \underline{\mathrm{C}}_{2} \mathrm{CH}_{2} \mathrm{O}-\right.$ ); LC-MS: $431.1(\mathrm{M}+\mathrm{H})^{+} ;{ }^{13} \mathrm{C}-\mathrm{NMR}$ (DMSO-d $\left.{ }_{6}\right) \delta$ : 156.36, 154.04 (C-7), 153.35 (C-6), 150.01 (C-10), 141.53 (C-9), 135.74 (C-1'), 128.37, 128.26, 124.46, 120.85, 120.26, 117.61, 117.33, 107.05 (C-5), 103.94 (C-4), 100.10 (C-8), 65.83 $\left(\mathrm{ClCH}_{2} \mathrm{CH}_{2} \underline{\mathrm{CH}_{2} \mathrm{O}-}\right), 56.80\left(-\mathrm{OCH}_{3}\right), 41.78\left(\mathrm{Cl}^{-} \mathrm{CH}_{2} \mathrm{CH}_{2} \mathrm{CH}_{2} \mathrm{O}-\right), 31.44\left(\mathrm{ClCH}_{2} \underline{\mathrm{CH}}_{2} \mathrm{CH}_{2} \mathrm{O}-\right)$; Anal. Calcd. for $\mathrm{C}_{18} \mathrm{H}_{15} \mathrm{ClF}_{4} \mathrm{~N}_{4} \mathrm{O}_{2}$ : C 50.19, $\mathrm{H}$ 3.51, N 13.01; Found: C 50.17, H 3.53, N 13.00.

7-(3-Chloropropoxy)-6-methoxy-4-(3-trifluoromethylanilino)-1,2,3-benzotriazine (8q): Yield: 75.2\%; mp: $180-181^{\circ} \mathrm{C}$. IR (KBr): $3438,2925,1623,1576,1510,1448,1244,799 \mathrm{~cm}^{-1}$; ${ }^{1} \mathrm{H}-\mathrm{NMR}$ (DMSO- $d_{6}$ ) $\delta: 9.81(1 \mathrm{H}, \mathrm{s}, \mathrm{NH}), 8.30$ (1H, s, H-2'), 8.25 (1H, d, $J=8.4 \mathrm{~Hz}, \mathrm{H}-6$ ') 7.94 (1H, s, H-8), 7.70 (1H, d, $J$ $=7.8 \mathrm{~Hz}, \mathrm{H}-5$ '), $7.66(1 \mathrm{H}, \mathrm{s}, \mathrm{H}-5), 7.51(1 \mathrm{H}, \mathrm{d}, J=8.1 \mathrm{~Hz}, \mathrm{H}-4$ '), $4.38(2 \mathrm{H}, \mathrm{t}, J=6.0 \mathrm{~Hz}$, $\left.\mathrm{ClCH}_{2} \mathrm{CH}_{2} \underline{\mathrm{C}}_{2} \mathrm{O}-\right), 4.06\left(3 \mathrm{H}, \mathrm{s},-\mathrm{OCH}_{3}\right), 3.84\left(2 \mathrm{H}, \mathrm{t}, J=6.4 \mathrm{~Hz}, \mathrm{ClC}_{2} \mathrm{CH}_{2} \mathrm{CH}_{2} \mathrm{O}-\right), 2.29(2 \mathrm{H}, \mathrm{m}$, $\mathrm{ClCH}_{2} \underline{\mathrm{CH}}_{2} \mathrm{CH}_{2} \mathrm{O}-$ ); LC-MS: $413.1(\mathrm{M}+\mathrm{H})^{+} ;{ }^{13} \mathrm{C}-\mathrm{NMR}$ (DMSO-d 6 ) $\delta$ : 154.10 (C-7), 153.41 (C-6), 150.14 (C-10), 141.66 (C-9), 139.87 (C-1'), 129.88, 129.53, 129.32, 125.71, 119.93, 118.17, 107.09 $(\mathrm{C}-5), \quad 104.11 \quad(\mathrm{C}-4), \quad 100.14 \quad(\mathrm{C}-8), \quad 65.85 \quad\left(\mathrm{ClCH}_{2} \mathrm{CH}_{2} \mathrm{CH}_{2} \mathrm{O}-\right), \quad 56.83 \quad\left(-\mathrm{OCH}_{3}\right), \quad 41.84$ 
$\left(\mathrm{Cl}_{\mathrm{CH}} \mathrm{CH}_{2} \mathrm{CH}_{2} \mathrm{O}\right), 31.45\left(\mathrm{ClCH}_{2} \mathrm{CH}_{2} \mathrm{CH}_{2} \mathrm{O}-\right)$; Anal. Calcd. for $\mathrm{C}_{18} \mathrm{H}_{16} \mathrm{ClF}_{3} \mathrm{~N}_{4} \mathrm{O}_{2}$ : C 52.37, $\mathrm{H}$ 3.91, N 13.57; Found: C 52.32, H 3.94, N 13.56.

4-Anilino-7-(3-chloropropoxy)-6-methoxy-1,2,3-benzotriazine (8r): Yield: 70.1\%; mp: $243{ }^{\circ} \mathrm{C}$. IR (KBr): 3435, 2922, 1614, 1566, 1502, 1447, 1421, 1285, 1241, 1108, 850, $744 \mathrm{~cm}^{-1}$; ${ }^{1} \mathrm{H}-\mathrm{NMR}$

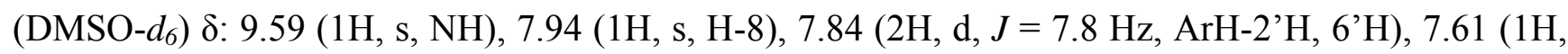
s, H-5), 7.45 (2H, t, $J=7.8 \mathrm{~Hz}, \mathrm{ArH}-3$ 'H, 5'H), 7.18 (1H, t, $J=7.5 \mathrm{~Hz}, \operatorname{ArH}-4$ 'H), 4.37 (2H, t, $J=6.0$ $\left.\mathrm{Hz}, \mathrm{ClCH}_{2} \mathrm{CH}_{2} \mathrm{CH}_{2} \mathrm{O}-\right), 4.04\left(3 \mathrm{H}, \mathrm{s},-\mathrm{OCH}_{3}\right), 3.84\left(2 \mathrm{H}, \mathrm{t}, J=6.3 \mathrm{~Hz}, \mathrm{ClCH}_{2} \mathrm{CH}_{2} \mathrm{CH}_{2} \mathrm{O}-\right), 2.29(2 \mathrm{H}, \mathrm{m}$, $\mathrm{ClCH}_{2} \mathrm{CH}_{2} \mathrm{CH}_{2} \mathrm{O}-$ ); LC-MS: $345.2(\mathrm{M}+\mathrm{H})^{+} ;{ }^{13} \mathrm{C}-\mathrm{NMR}$ (DMSO-d $)_{6} \delta: 153.88$ (C-7), 153.17 (C-6), 150.28 (C-10), 141.50 (C-9), 138.83 (C-1'), 128.68 (C-3', C-5'), 124.03 (C-4'), 122.88 (C-2', C-6'), 107.01 (C-5), 104.02 (C-4), 100.31 (C-8), 65.78 ( $\mathrm{ClCH}_{2} \mathrm{CH}_{2} \underline{\left.\mathrm{CH}_{2} \mathrm{O}-\right),} 56.81 \quad\left(-\mathrm{OCH}_{3}\right), 41.89$ $\left(\mathrm{ClCH}_{2} \mathrm{CH}_{2} \mathrm{CH}_{2} \mathrm{O}-\right), 31.48\left(\mathrm{ClCH}_{2} \mathrm{CH}_{2} \mathrm{CH}_{2} \mathrm{O}-\right)$; Anal. Calcd. for $\mathrm{C}_{17} \mathrm{H}_{17} \mathrm{ClN}_{4} \mathrm{O}_{2}: \mathrm{C}$ 59.22, $\mathrm{H}$ 4.97, N 16.25; Found: C 59.28, H 4.96, N 16.17.

Antiproliferative activity assay

Cell lines: The cell lines used were obtained from ATCC (Rockville, MD, USA). T47D human breast cancer cells, DU145 and PC-3 human prostate cancer cells were cultured in RPMI1640 medium (Gibco; New York, NY, USA) supplemented with 100 units $/ \mathrm{mL}$ penicillin, $100 \mu \mathrm{g} / \mathrm{mL}$ streptomycin, 1 $\mathrm{mM}$ L-glutamine, $5 \mu \mathrm{g} / \mathrm{mL}$ insulin and $10 \%(\mathrm{v} / \mathrm{v})$ heat-inactivated fetal bovine serum (FBS). MVECs, LL/2 murine lewis lung carcinoma cells and B16F0 melanoma cells were cultured in DMEM with 4 mM L-glutamine adjusted to contain $4.50 \mathrm{~g} / \mathrm{L}$ glucose and $10 \%(\mathrm{v} / \mathrm{v})$ heat-inactivated FBS.

Cell growth inhibition assay: The antiproliferative activities of these compounds were determined by the MTT assay. Cells $\left(2 \times 10^{3}\right.$ cells/well in 96-well plates) were incubated for $24 \mathrm{~h}$, then various concentrations of each compound were added to each well and the cells were cultured for another 4 days at $37{ }^{\circ} \mathrm{C}$. MTT solution $(50 \mu \mathrm{L}$ of $2 \mathrm{mg} / \mathrm{mL})$ was added per well and the culture continued for an additional $4 \mathrm{~h}$. The medium was removed by aspiration and the cells were dissolved in $200 \mu \mathrm{L}$ DMSO. The absorbance at $570 \mathrm{~nm}$ was measured in the 96-well plate reader. Growth inhibition is reported as compared to untreated cells $(\%)$ and $\mathrm{GI}_{50}$ concentration was calculated [18].

\section{Acknowledgements}

This work is supported by the Natural Science Foundation of Liaoning Province of China (No. 20062060).

\section{References}

1. Ferrara, N. Vascular endothelial growth factor as a target for anticancer therapy. Oncologist 2004, 9, Suppl 1, 2-10.

2. Poon, R. T.; Fan, S. T.; Wong, J. Clinical implications of circulating angiogenic factors in cancer patients. J. Clin. Oncol. 2001, 19, 1207-1225. 
3. Toi, M.; Matsumoto, T.; Bando, H. Vascular endothelial growth factor: its prognostic, predictive, and therapeutic implications. Lancet Oncol. 2001, 2, 667-673.

4. Wood, J. M.; Bold, G.; Buchdunger, E.; Cozens, R.; Ferrari, S.; Frei, J.; Hofmann, F.; Mestan, J.; Mett, H.; O’Reilly, T.; Persohn, E.; Rosel, J.; Schnell, C.; Stover, D.; Theuer, A.; Towbin, H.; Wenger, F.; Woods-Cook, K.; Menrad, A.; Siemeister, G.; Schirner, M.; Thierauch, K.-H.; Schneider, M. R.; Drevs, J.; Martiny-Baron, G.; Totzke, F.; Marme, D. PTK787/ZK 222584, a novel and potent inhibitor of vascular endothelial growth factor receptor tyrosine kinases, impairs vascular endothelial growth factorinduced responses and tumor growth after oral administration. Cancer Res. 2000, 60, 2178-2189.

5. Bold, G.; Altmann, K. H.; Frei, J.; Lang, M.; Manley, P. W.; Traxler, P.; Wietfeld, B.; Bruggen, J.; Buchdunger, E.; Cozens, R.; Ferrari, S.; Furet, P.; Hofmann, F.; Martiny-Baron, G.; Mestan, J.; Rosel, J.; Sills, M.; Stover, D.; Acemoglu, F.; Boss, E.; Emmenegger, R.; Lasser, L.; Masso, E.; Roth, R.; Schlachter, C.; Vetterli, W. New anilinophthalazines as potent and orally well absorbed inhibitors of the VEGF receptor tyrosine kinases useful as antagonists of tumor-driven angiogenesis. J. Med. Chem. 2000, 43, 2310-2323.

6. Heymach, J. V. ZD6474--clinical experience to date. Brit. J. Cancer 2005, 92 Suppl 1, S14-20.

7. Sahtornsumetee, S.; Rich, J. N. Vandetanib (ZD6474), a novel multitargeted kinase inhibitor, in cancer therapy. Drugs Today 2006, 42, 657-670.

8. Joensuu, H.; De Braud, F.; Coco, P.; De Pas, T.; Putzu, C.; Spreafico, C.; Bono, P.; Bosselli, S.; Jalava, T.; Laurent, D.; Casali, P. G. Phase II, open-label study of PTK787/ZK222584 for the treatment of metastatic gastrointestinal stromal tumors resistant to imatinib mesylate. Ann. Oncol. 2008, 19, 173-177.

9. Thomas, A. L.; Trarbach, T.; Bartel, C.; Laurent, D.; Henry, A.; Poethig, M.; Wang, J.; Masson, E.; Steward, W.; Vanhoefer, U.; Wiedenmann, B. A phase IB, open-label dose-escalating study of the oral angiogenesis inhibitor PTK787/ZK 222584 (PTK/ZK), in combination with FOLFOX4 chemotherapy in patients with advanced colorectal cancer. Ann. Oncol. 2007, 18, 782-788.

10. Kovacs, M. J.; Reece, D. E.; Marcellus, D.; Meyer, R. M.; Mathews, S.; Dong, R. P.; Eisenhauer, E. A phase II study of ZD6474 (Zactima, a selective inhibitor of VEGFR and EGFR tyrosine kinase in patients with relapsed multiple myeloma--NCIC CTG IND.145. Invest. New Drugs 2006, 24, 529-535.

11. Lee, D. Phase II data with ZD6474, a small-molecule kinase inhibitor of epidermal growth factor receptor and vascular endothelial growth factor receptor, in previously treated advanced nonsmall-cell lung cancer. Clin. Llung Cancer 2005, 7, 89-91.

12. Miller, K. D.; Trigo, J. M.; Wheeler, C.; Barge, A.; Rowbottom, J.; Sledge, G.; Baselga, J. A multicenter phase II trial of ZD6474, a vascular endothelial growth factor receptor-2 and epidermal growth factor receptor tyrosine kinase inhibitor, in patients with previously treated metastatic breast cancer. Clin. Cancer Res. 2005, 11, 3369-3376.

13. Gueto, C.; Ruiz, J. L.; Torres, J. E.; Méndez, J.; Vivas-Reyes, R. Three-dimensional quantitative structure-activity relationship studies on novel series of benzotriazine based compounds acting as Src inhibitors using CoMFA and CoMSIA. Bioorg. Med. Chem. 2008, 16, 2439-2447.

14. Noronha, G.; Barrett, K.; Cao, J.; Dneprovskaia, E.; Fine, R.; Gong, X.; Gritzen, C.; Hood, J.; Kang, X.; Klebansky, B.; Li, G.; Liao, W.; Lohse, D.; Mak, C. C.; McPherson, A.; Palanki, M. S.; 
Pathak, V. P.; Renick, J.; Soll, R.; Splittgerber, U.; Wrasidlo, W.; Zeng, B.; Zhao, N.; Zhou, Y. Discovery and preliminary structure-activity relationship studies of novel benzotriazine based compounds as Src inhibitors. Bioorg. Med. Chem. Lett. 2006, 16, 5546-5550.

15. Wissner, A.; Floyd, M. B.; Johnson, B. D.; Fraser, H.; Ingalls, C.; Nittoli, T.; Dushin, R. G.; Discafani, C.; Nilakantan, R.; Marini, J.; Ravi, M.; Cheung, K.; Tan, X.; Musto, S.; Annable, T.; Siegel, M. M.; Loganzo, F. 2-(Quinazolin-4-ylamino)-[1,4]benzoquinones as covalent-binding, irreversible inhibitors of the kinase domain of vascular endothelial growth factor receptor-2. $J$. Med. Chem. 2005, 48, 7560-7581.

16. Siddiqui, M. S. S.; Stevens, M. F. G. Triazines and related products. Part XI. Dimroth rearrangements of 3-substituted 3,4-dihydro-4-imino-1,2,3-benzotriazines in acetic acid. J. Chem. Soc., Perkin Trans. 1, 1974, 609-610.

17. Hess-Stumpp, H.; Haberey, M.; Thierauch, K. H. PTK 787/ZK 222584, a tyrosine kinase inhibitor of all known VEGF receptors, represses tumor growth with high efficacy. Chembiochem 20056 , 550-557.

18. Lu, M.; Xia, L.; Luo, D.; Waxman, S.; Jing, Y. Dual effects of glutathione-S-transferase pi on As2O3 action in prostate cancer cells: enhancement of growth inhibition and inhibition of apoptosis. Oncogene 2004, 23, 3945-3952.

Sample Availability: Contact the authors.

(C) 2008 by the authors; licensee Molecular Diversity Preservation International, Basel, Switzerland. This article is an open-access article distributed under the terms and conditions of the Creative Commons Attribution license (http://creativecommons.org/licenses/by/3.0/). 